\title{
ARTICLE Interleukin-7 protects against bacterial respiratory infection by promoting IL-17A-producing innate T-cell response
}

\author{
Maya Hassane', Youenn Jouan ${ }^{2,3,4}$, Florent Creusat ${ }^{2,3}$, Daphnée Soulard ${ }^{1}$, Chloé Boisseau ${ }^{2,3}$, Loïc Gonzalez ${ }^{2,3}$, Emmanuel C. Patin ${ }^{1}$, \\ Nathalie Heuzé-Vourc' ${ }^{2,3}$, Jean-Claude Sirard ${ }^{1}$, Christelle Faveeuw ${ }^{1}$, François Trottein ${ }^{1}$, Mustapha Si-Tahar ${ }^{2,3}$, Thomas Baranek ${ }^{2,3}$ and \\ Christophe Paget ${ }^{1,2,3}$
}

\begin{abstract}
Interleukin-7 (IL-7) is a critical cytokine in B- and T-lymphocyte development and maturation. Recent evidence suggests that IL-7 is a preferential homeostatic and survival factor for ROR $\mathrm{t}^{+}$innate $\mathrm{T}$ cells such as natural killer T (NKT) cells, $\gamma \delta T$ cells, and mucosalassociated invariant T (MAIT) cells in the periphery. Given the important contribution of these populations in antibacterial immunity at barrier sites, we questioned whether IL-7 could be instrumental in boosting the local host immune response against respiratory bacterial infection. By using a cytokine-monoclonal antibody approach, we illustrated a role for topical IL-7 delivery in increasing the pool of RORyt ${ }^{+}$IL-17A-producing innate T cells. Prophylactic IL-7 treatment prior to Streptococcus pneumoniae infection led to better bacterial containment, a process associated with increased neutrophilia and that depended on $\gamma \delta T$ cells and IL-17A. Last, combined delivery of IL-7 and a-galactosylceramide (a-GalCer), a potent agonist for invariant NKT (iNKT) cells, conferred an almost total protection in terms of survival, an effect associated with enhanced IL-17 production by innate T cells and neutrophilia. Collectively, we provide a proof of concept that IL-7 enables fine-tuning of innate T- cell functions. This might pave the way for considering IL-7 as an innovative biotherapeutic against bacterial infection.
\end{abstract}

Mucosal Immunology (2020) 13:128-139; https://doi.org/10.1038/s41385-019-0212-y

\section{INTRODUCTION}

Innate $T$ cells represent a class of thymus-derived T lymphocytes that comprise three main lineages, namely natural killer T (NKT) cells, $\gamma \delta T$ cells, and mucosal-associated invariant T (MAIT) cells. ${ }^{1}$ These preset cells play a role in a large panel of immune responses including cancer, infection, inflammation, and metabolic disorders. $^{2-5}$ This is mainly due to their versatile nature including immunomodulation and cytotoxic properties. In this respect, attempts to harness their functions for therapeutic purposes are currently under intense investigation. Selective exogenous activation of innate T-cell subsets has been rendered possible by using various T-cell receptor (TCR)-specific antigens (Ags) of non-peptide nature. ${ }^{6-9}$ For instance, the glycolipid a-galactosylceramide (aGalCer), a potent and selective Ag for invariant NKT (iNKT) cells, has proven fruitful in preclinical models of cancer and infection. . $^{70}$ Prophylactic i.n. instillation of a-GalCer protects mice in various models of lung infections, including pneumococcus-induced pneumonia, ${ }^{11,12}$ a mechanism that relies on cognate iNKT cell activation and transactivation of innate effector cells such as neutrophils. ${ }^{12}$ However, the possibility to harness all innate T-cell lineages at once (e.g., by using a combination of specific Ags or a universal innate T-cell activator) has never been explored.

Interleukin-7 (IL-7) is a pleiotropic cytokine, mainly produced by stromal cells, ${ }^{13}$ that greatly contributes to B- and T-cell development in primary lymphoid organs, as well as the regulation of mature T-cell proliferation in the periphery. ${ }^{14} \mathrm{IL}-7$ signals through a heterodimer receptor (IL-7R) consisting of two chains: the a chain (CD127) and the common $\gamma$ chain (CD132), which is shared with many other cytokine receptors. ${ }^{15}$ Several IL7-based clinical studies have been initiated in various conditions including bone marrow transplantation, cancer, sepsis, and chronic viral infections. ${ }^{16}$ While IL-7 treatment appears to ameliorate the clinical outcomes, ${ }^{16}$ its systemic administration has been often associated with side effects. ${ }^{17}$ These secondary effects are likely a consequence of the high doses injected to achieve a biological response, considering the relatively short halflife of the protein. ${ }^{18}$ To deal with this major drawback, various approaches have been attempted to increase in vivo IL-7 half-life. Among those, binding of IL-7 to an anti-IL-7 mAb prior to in vivo administration was shown to increase its biological activity and pharmacokinetics. $^{19}$

Interestingly, IL-7 has been shown as an important factor for RAR-related orphan receptor gamma $t(\mathrm{ROR} p \mathrm{t})^{+} \mathrm{IL}-17$-producing innate T-cell survival and homeostasis in the periphery including $\gamma \delta T 17^{20}$ and $i N K T 17^{21}$ cells. An earlier study also revealed that IL-7 could increase IL-4 production by splenic iNKT-like cells. ${ }^{22}$ In addition, recent evidence points toward a preferential role for IL-7 in MAIT17 cells biology. ${ }^{23-26}$ This preferential response relies in large part on the high-density surface expression of IL-7R (CD127)

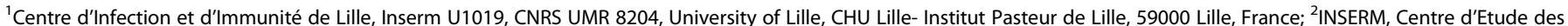

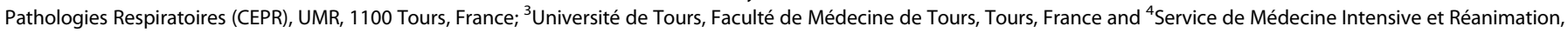
Centre Hospitalier Régional Universitaire, Tours, France

Correspondence: Christophe Paget (christophe.paget@inserm.fr)

These authors contributed equally: Maya Hassane, Youenn Jouan

Received: 29 May 2019 Revised: 24 September 2019 Accepted: 28 September 2019

Published online: 18 October 2019 
on these subsets, awarding them an undeniable advantage to uptake the limited levels of IL-7 in non-lymphoid tissues. Mechanistically, IL-7R signaling in these cells leads to the engagement of either STAT3 ${ }^{20,25}$ (for $\gamma \delta T 17$ and MAIT17 cells) or the PI3K/AKT/mTOR signaling pathway ${ }^{21}$ (for iNKT cells) culminating in enhanced survival and proliferation. Given the contribution of IL-17-producing innate $T$ cells in antimicrobial response at barrier sites, ${ }^{27,28}$ we hypothesized that local IL-7 pretreatment could bolster, in an innate T-cell-dependent manner, host defense against bacterial respiratory tract infection.

We demonstrate that intranasal (i.n.) instillation of IL-7/anti-IL-7 complex to naive mice increased the cellular pool of lung IL-17Aproducing innate $\mathrm{T}$ cells, with no detectable systemic effects. Upon Streptococcus pneumoniae infection, IL-7 pretreatment instigates an innate IL-17A-enriched environment in the lungs that boosts the early host antibacterial response. In addition, the combination of IL-7 with a-GalCer conferred better protection against lethal pneumonia compared with stand-alone treatments. We conclude that IL-7 can be instrumental to locally manipulate pulmonary innate T-cell functions, an observation that could be the basis for future strategies to fight against lethal bacterial infections.

\section{RESULTS}

Intranasal instillation of IL-7/M25 complex induces proliferation of lung RORyt ${ }^{+}$innate $\mathrm{T}$ cells

To investigate the effects of IL-7 instillation on lung lymphocyte homeostasis, we treated naive mice with the IL-7/M25 complex by the i.n. route (Fig. 1a). Three days after treatment cessation, we assessed the frequency and absolute number of lung immune populations. IL-7/M25 treatment did not influence the total number of live leukocytes or affect the relative proportion of conventional $B$ and $T$ cells in the lung tissue (Supplementary Fig. 1a, b). In contrast, it induced a significant increase in the three innate T-cell lineages, namely iNKT cells, $\gamma \delta T$ cells, and MAIT cells (Fig. 1b) by 2.1-, 3.3-, and 8.8-fold, respectively. Of note, stand-alone treatments with IL-7 or anti-IL-7 (M25) did not induce any modulation in innate T-cell frequencies (Supplementary Fig. 1c). Regarding the potential side effects associated with IL-7, ${ }^{17}$ it is worth mentioning that this treatment did not lead to measurable signs of hepatic toxicity (Supplementary Fig. 1d).

These differential effects on innate T-cell lineages may be linked to their divergent constitutive expression of IL-7R (CD127) (Supplementary Fig. 1e). Furthermore, consistent with CD127 expression (Fig. 1C), IL-7/M25 treatment preferentially increased RORyt $^{+}$innate $\mathrm{T}$ cells, although an effect was also observed on their RORyt ${ }^{-}$counterparts (Fig. 1d). It is worth mentioning that the effect observed on RORyt ${ }^{-}$cells was restricted to the $\mathrm{T}^{-b e t}{ }^{-}$ subset (Supplementary Fig. 1f).

Consistent with a proliferative effect for IL-7, 20,21 innate T cells displayed higher levels of Ki67 upon IL-7/M25 treatment (Supplementary Fig. 1g). Importantly, this effect was observed on both RORyt ${ }^{-}$and RORyt $^{+}{ }^{\text {iNKT }}$ and $\gamma \delta T^{2}$ cells early after treatment cessation, but was restricted to the RORyt ${ }^{+}$subsets later on (Fig. 1e). Of note, reminiscent with their higher constitutive expression of CD127 (Fig. 1c), both RORyt ${ }^{-}$and RORyt ${ }^{+}$MAIT cells conserved a phenotype of proliferative cells even 3 days after IL-7/ M25 treatment (Fig. 1e).

The elevated frequency of RORyt ${ }^{+}$innate T cells was sustained over 2 weeks after treatment cessation, while the effect on their RORyt $^{-}$counterparts appeared more transient (Fig. 1f). In addition, no modulation in total innate T-cell frequencies or $\mathrm{RORYt}^{+/-}$subset proportions was detected in the spleen of IL-7/ M25-treated mice (Supplementary Fig. 1h) suggesting a local effect. Altogether, these results indicate that i.n. instillation of IL7/M25 leads to a local and prolonged elevated frequency/number of lung RORyt ${ }^{+}$innate T cells, an effect likely due to enhanced proliferation.

IL-7 treatment increases the capacity of pulmonary innate $\mathrm{T}$ cells to produce IL-17A

To assess the effects of IL-7/M25 treatment on innate $T$ cell's cytokine profile, total lung leukocytes from control or IL-7/M25treated mice were stimulated ex vivo by using PMA/ionomycin for $4 \mathrm{~h}$. Intracellular staining indicated increased frequency (Fig. 2a) and absolute numbers (Fig. 2b) of IL-17A-producing innate T cells in lungs from IL-7/M25-treated mice. On the other hand, IFN- $\gamma$ production by innate $T$ cells was unchanged upon IL-7/M25 treatment (Supplementary Fig. 2a). In addition, the relative proportions of IL-17A-producing innate T-cell populations were unchanged upon IL-7/M25 treatment, suggesting no significant preferential effects on a peculiar lineage (Fig. 2C). Of note, no significant production of $\mathrm{IL}-17 \mathrm{~A}^{+}$by innate $\mathrm{T}$ cells could be observed between groups without restimulation (Supplementary Fig. 2b), suggesting that IL-7 supports their homeostasis rather than providing activation cues. In line, in vitro stimulation of total lung mononuclear cells from IL-7/M25-treated mice resulted in higher levels of IL-17A, but not IFN- $\gamma$ in culture supernatants compared with controls (Fig. $2 \mathrm{~d}$ ). To assess the relative contribution of innate T-cell lineages in this pro-IL-17A effect, lung leukocytes from saline- or IL-7/M25-treated WT, $\gamma \delta T$ cell-deficient $\left(\right.$ Tcrd $\left.^{-1-}\right)$, and $i$ NKT cell-deficient $\left(\operatorname{Traj} 18^{-/-}\right)$mice were stimulated ex vivo. While both $\gamma \delta T$ cell- and iNKT cell deficiencies significantly reduced IL-17A production in PBS-treated mice, the IL-7-driven pro-IL-17A effect was significantly reduced in $\mathrm{Tcrd}^{-/-}$ mice while being only slightly impacted in $\mathrm{Ja}^{-18^{-1}}$ mice (Fig. 2e). Collectively, our data suggest that IL-7/M25 treatment increases IL$17 \mathrm{~A}$ secretion in lungs, an effect partially dependent on $\gamma \delta \mathrm{T}$ cells.

IL-7/M25 treatment increases IL-17A production by innate T cells in response to pneumococcal infection

Early IL-17A production by innate T cells is essential for bacterial containment and mouse survival during pneumococcal infection. ${ }^{11,29-33}$ Thus, we assessed the effects of IL-7/M25 on host innate immune response to pneumococcus-induced pneumonia, by using a pathogenic strain of $S$. pneumoniae serotype 1, a major serotype associated with invasive disease in humans. ${ }^{34}$ By using intracellular cytokine staining, we observed that innate $T$ cells were able to produce IL-17A following $S$. pneumoniae infection (Fig. 3a). An increase in the relative proportion and absolute number of IL-17A-producing innate T cells was observed in IL-7/ M25-pretreated infected mice (Fig. 3a). Of note, the relative proportion of IL-17A-producing MAIT cells was not influenced upon treatment (Fig. 3a). On the other hand, no change in IFN- $\gamma$ producing innate T cells was observed upon IL-7/M25 treatment (Fig. 3b).

IL-23 and IL-1 $\beta$ greatly contribute to IL-17A production by innate $T$ cells. $^{25,35,36}$ of note, IL-7/M25 pretreatment did not modulate the levels of these cytokines in the lungs of infected mice (Fig. 3c). In line with the positive effect of IL-17A on neutrophil recruitment, ${ }^{37}$ we observed higher levels of the neutrophil chemoattractant CXCL1 in lung homogenates of IL-7/ M25-treated infected mice (Fig. 3d). In addition, a higher number of neutrophils (Fig. 3e) and increased myeloperoxidase release (Fig. 3f) were detected in the lung of IL-7/M25-pretreated infected mice. Taken as a whole, these results indicate that IL-7/M25 prophylactic treatment leads to an increase in IL-17A production by innate $T$ cells and neutrophil recruitment/activity upon S. pneumoniae infection.

IL-7/M25 treatment reduces bacterial burden in an IL-17A-, neutrophil-, and $\gamma \delta \mathrm{T}$ cell-dependent manner

In addition to the immunological parameters, we also evaluated the outcome of IL-7/M25 pretreatment on bacterial burden and 
a

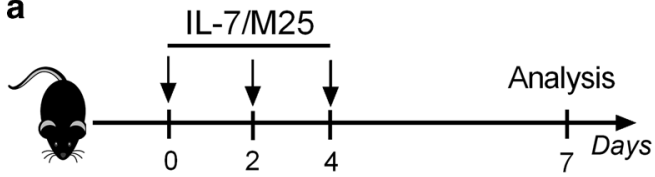

b

PBS

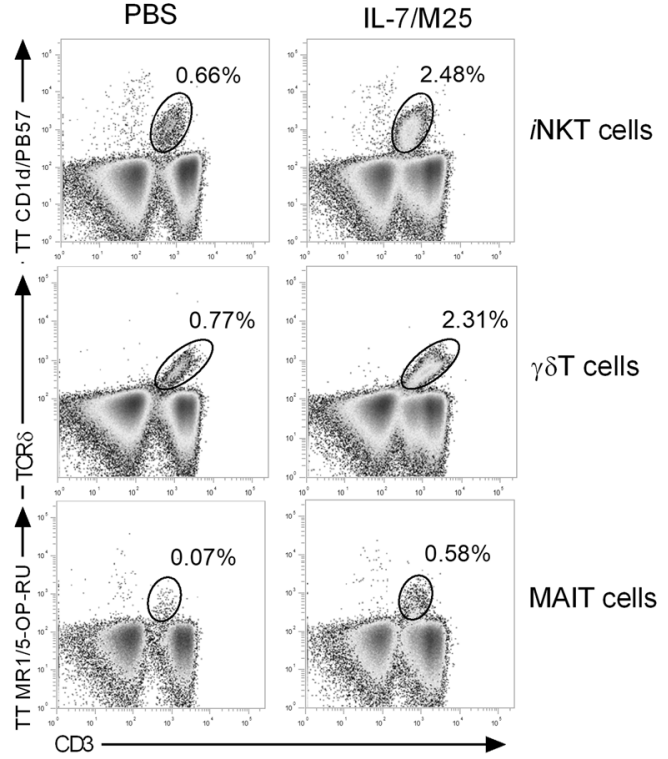

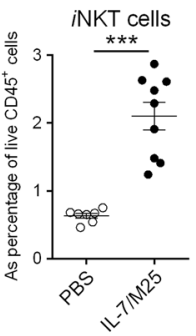
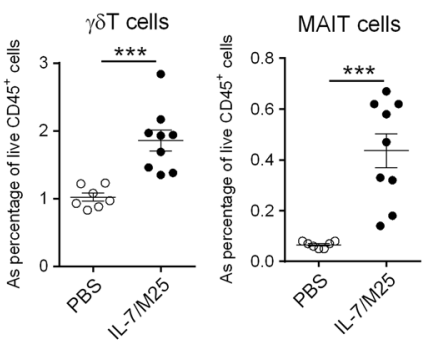

c
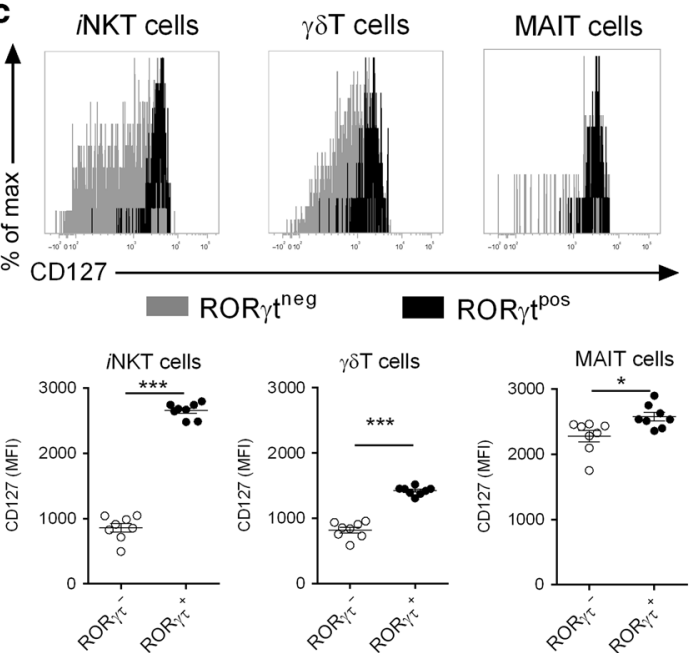

d

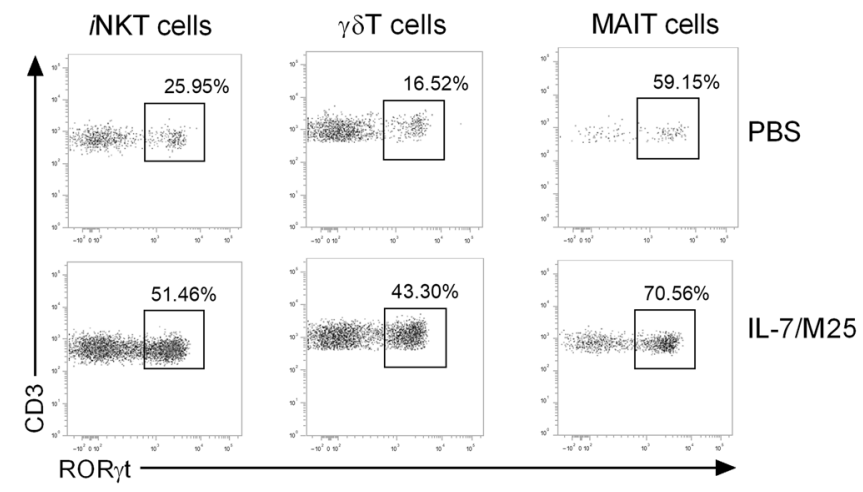

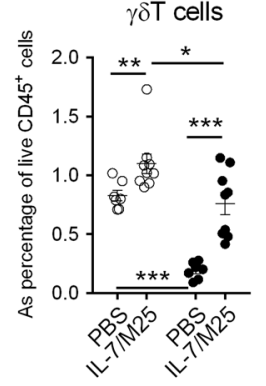

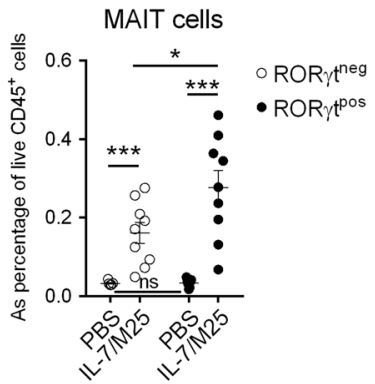

e
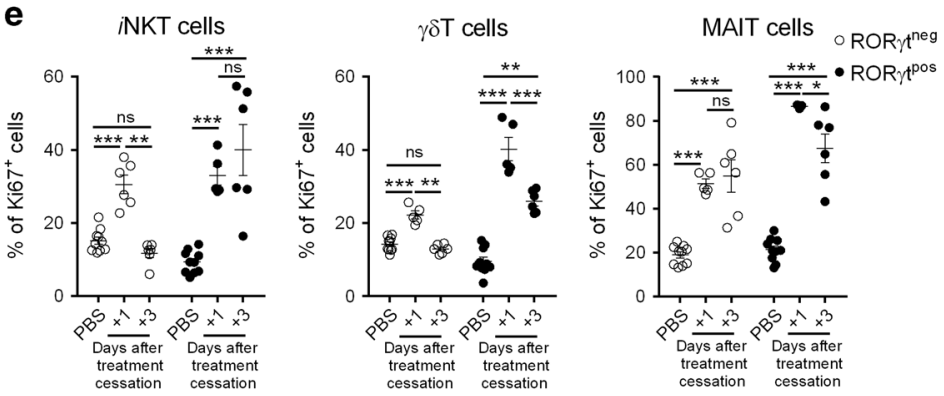
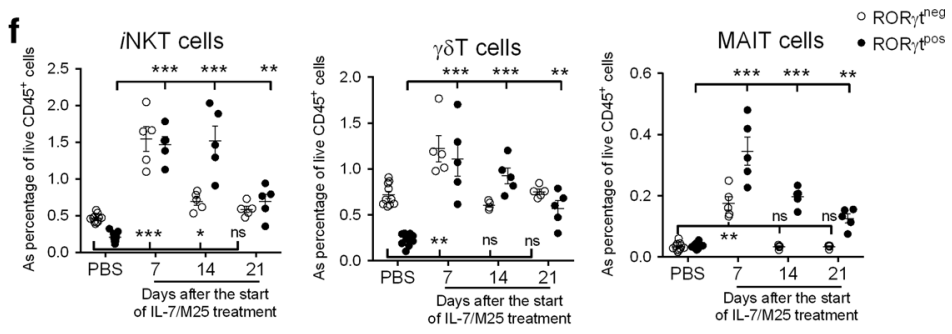

survival following lethal pneumococcus-induced pneumonia. IL-7/ M25 treatment significantly reduced bacterial burden in the lungs as well as bacterial dissemination (Fig. 4a). Of note, the antipneumococcus effect could still be observed in mice that were infected a week after treatment cessation (Supplementary Fig. 3a). To address the mechanisms involved in this antibacterial response, $1117 a^{-1-}$ mice were pretreated with IL-7/M25 before
S. pneumoniae infection. The protective effect of IL-7/M25 on bacterial loads was abrogated in $1117 a^{-1-}$ mice (Fig. 4b). Since neutrophils greatly contribute to pneumococcus clearance, the antibacterial effect of IL-7/M25 pretreatment was evaluated in the absence of neutrophils. Neutrophil depletion in saline-treated controls led to enhanced bacterial outgrowth in lungs and spleen (Fig. 4c). In addition, the protective antibacterial effect of IL-7/M25 
Fig. 1 Intranasal instillation of IL-7/M25 potentiates IL-17A-producing lung innate T cells. a WT C57BL/6J mice received three intranasal doses of IL-7/M25 or saline every other day. Mice were euthanized at day 7, and organs were collected for further analysis. b-h Mice were treated as depicted in panel a. b Frequencies of lung iNKT $\left(\mathrm{CD}_{4} 5^{+}, \mathrm{CD}^{+}\right.$, and PBS57/CD1d tetramer $\left.{ }^{+}\right), \gamma \delta \mathrm{T}\left(\mathrm{CD} 45^{+}, \mathrm{CD}^{+}\right.$, and TCR $\left.{ }^{+}\right)$, and $\mathrm{MAIT}\left(\mathrm{CD} 45^{+}\right.$, $\mathrm{CD}^{+}$, and 5-OP-RU/MR1 tetramer ${ }^{+}$) cells in PBS- or IL-7/M25-treated mice were evaluated by flow cytometry. Representative dot plots are shown in the upper panel. Individual values and means \pm SEM of innate T-cell frequencies from two independent experiments are shown (8-9 mice/group) in the lower panel. c Expression of CD127 on ROR $\gamma \mathrm{t}^{-}$(gray line) and ROR $\gamma \mathrm{t}^{+}$(black line) innate T cells. Representative histograms are shown in the upper panel. Individual values and means \pm SEM of mean fluorescence intensity from two independent experiments are shown (eight mice/group) in the lower panel. d Expression of RORyt in innate T cells. Representative dot plots of ROR $\gamma \mathrm{t}$ expression in innate $\mathrm{T}$ cells are shown in the upper panel. Individual values and means \pm SEM from two independent experiments are shown (8-9 mice/group) in the lower panel. e Frequencies of $\mathrm{Ki}^{+} 7^{+}$cells in innate T-cell ROR $\gamma \mathrm{t}^{-}$versus ROR $\gamma \mathrm{t}^{+}$subsets at day +1 and +3 after treatment cessation. Individual values and means \pm SEM from one representative experiment out of two is shown (five mice/group). $f$ Kinetics of lung ROR $\mathrm{t}^{-}$and $\mathrm{ROR}_{\mathrm{t}} \mathrm{t}^{+}$innate T cells after IL-7/M25 treatment cessation. Individual values and means $\pm \mathrm{SEM}$ from one representative experiment out of two is shown (five mice/group). ns not significant, ${ }^{*} P<0.05 ;{ }^{* *} P<0.01 ;{ }^{* *} P<0.001$

was blunted in the absence of neutrophils (Fig. 4c). As our data suggested a preferential role for $\gamma \delta T$ cells in the pro-IL-17A effect mediated by IL-7/M25 (Fig. 2e), we evaluated their contribution in the IL-7/M25-dependent control of bacterial growth. In line with recent reports, 29,30 $\gamma \delta \mathrm{T}$-cell deficiency resulted in increased bacterial loads in the lungs and spleen (Fig. 4d). Furthermore, IL$7 / \mathrm{M} 25$ failed to lower the number of pneumococci in lungs and spleen of $\gamma \delta \mathrm{T}$-cell-deficient mice. Conversely, IL-7-dependent antibacterial response was not affected in Traj $18^{-1}$ mice (Supplementary Fig. 3b). We next turned to analyze the effect of IL-7 treatment on survival. Although IL-7/M25 pretreatment resulted in improved bacterial containment in WT mice, this was not associated with any benefit on survival (Fig. 4e). Taken together, IL-7/M25 prophylactic treatment allows bacterial containment in an IL-17A-, $\gamma \delta \mathrm{T}$ cell-, and neutrophil-dependent manner, but does not positively influence mouse survival.

Intranasal instillation of a low dose of a-GalCer confers partial protection against $S$. pneumoniae-induced pneumonia with limited lung iNKT cell hyporesponsiveness

Since IL-7/M25 treatment did not positively influence survival, we postulated that its combination with an innate T-cell stimulator such as a-GalCer could lead to increased protective effects. In previous studies, high doses of a-GalCer conferred, a iNKT celldependent, complete protection against pneumococcal infection, ${ }^{11,12}$ offering no room for a potential synergistic effect when combined with IL-7/M25. Thus, we searched for a suboptimal dose enabling iNKT cell activation and partial protection against S. pneumoniae-induced pneumonia. To this aim, mice were i.n. exposed to a high $(2 \mu \mathrm{g})$ or low $(25 \mathrm{ng})$ dose of $\mathrm{a}-\mathrm{GalCer}$, and the ensuing local innate immune response was evaluated. Treatment with the high-but not with low-dose resulted in a decrease in lung iNKT cell frequencies (Fig. 5a), a phenomenon likely due to activation-induced TCR downmodulation. ${ }^{38}$ Moreover, iNKT cells presented a phenotype of activated cells as judged by CD69 overexpression (Fig. 5b). Low and high doses of a-GalCer induced IFN- $\gamma$ and IL-17A production by lung iNKT cells (Fig. $5 \mathrm{c}$ ) albeit in a dose-dependent manner. Next, the protective effect of the two doses of a-GalCer was evaluated. Consistent with previous reports, ${ }^{11,12}$ we observed that instillation of a high dose of aGalCer $16 \mathrm{~h}$ prior to $S$. pneumoniae inoculation conferred a complete protection, while low dose only protected a small proportion of the mice (Fig. $5 d$ ).

Importantly, a-GalCer-mediated iNKT cell activation culminates in a long-term state of hypo- or unresponsiveness. ${ }^{39,40}$ Thus, we evaluated whether the dose of a-GalCer might influence the appearance of such a phenomenon (Fig. 5e). Lung iNKT cells from a-GalCer-experienced mice displayed lower ability to produce IFN$\gamma$ upon in vivo a-GalCer rechallenge compared with vehiclepretreated mice (Fig. 5f), although this effect was less marked with the low dose. Surprisingly, iNKT cells retained their capacity to produce IL-17A upon a-GalCer rechallenge (Fig. 5f). In addition, iNKT cells from a-GalCer-treated mice overexpressed programmed cell death 1 (PD-1) at cell surface (Fig. 5g), a marker of iNKT cell anergy. ${ }^{41}$ This effect was significantly lower with the low dose of a-GalCer (Fig. $5 \mathrm{~g}$ ). In addition, transactivation of $\gamma \delta$ T and MAIT cells was almost maintained in mice that were pretreated with a low dose of a-GalCer while being blunted with the high dose (Fig. 5h). However, this effect was unlikely due to anergy, but rather the consequence of $i$ NKT hyporesponsiveness, since the levels of PD-1 on $\gamma \delta T$ and MAIT cells remained constant after a-GalCer treatment (Supplementary Fig. 4). Collectively, these data indicate that i.n. instillation of a low dose of a-GalCer confers partial protection against lethal pneumococcus-induced pneumonia, but limits the appearance of long-term iNKT cell hyporesponsiveness.

Combination of IL-7 with a suboptimal dose of a-GalCer enhances the survival of $S$. pneumoniae-infected mice

Having determined a suboptimal dose of a-GalCer, its activating capacity on lung innate $T$ cells was evaluated in IL-7/M25pretreated mice (Fig. 6a). IL-7/M25 pretreatment led to a higher proportion of $\mathrm{IL}_{-17 \mathrm{~A}^{+}}$innate $\mathrm{T}$ cells in response to $\mathrm{a}-\mathrm{GalCer}$ (Fig. 6b) while their IFN- $\gamma^{+}$counterparts remained unchanged (Supplementary Fig. 5). In concert, a-GalCer-induced neutrophilia was increased after IL-7 instillation (Fig. 6c). Thus, the survival of mice upon S. pneumoniae infection was followed upon IL-7/aGalCer combinatorial prophylactic treatment. While stand-alone treatments with IL-7/M25 or a-GalCer conferred little to any protection ( 0 and $27 \%$, respectively), their combination significantly improved mouse survival (76\%) (Fig. 6d). Altogether, these results indicate that combinatorial treatment with IL-7 and aGalCer led to an enhanced IL-17 innate response and allows synergistic protective effects upon S. pneumoniae-induced lethal pneumonia compared with stand-alone treatments.

\section{DISCUSSION}

Harnessing innate T cells for clinical purposes is currently under important investigations. To date, most of the studies aiming at manipulating innate T-cell functions used molecules (e.g., specific TCR agonists) that enable strong and swift activation of a particular innate T-cell lineage. Here, we reported that IL-7 instillation can be instrumental to foster the pool of lung innate T cells endowed with IL-17A production, including $\gamma \delta T$, iNKT, and MAIT cells. IL-7 triggers innate RORyt $^{+}$T-cell proliferation culminating in a long-term pre-armed IL-17A-enriched local environment. This pool of preset cells with specific functions can thus be activated "on-demand" conferring to the host a timely advantage especially during infections.

Understanding the mechanisms underlying the preferential effect of IL-7 on IL-17A-producing innate T cells will require further investigations. However, the high-density expression of IL-7R on RORyt $^{+}$innate $\mathrm{T}$ cells can partially explain this phenomenon. A differential localization of innate T-cell subsets (e.g., RORyt ${ }^{+}$vs. RORYt $^{-}$) within the lung tissue might also be important. In line, previous reports indicated that IL-17A-producing iNKT and 
a

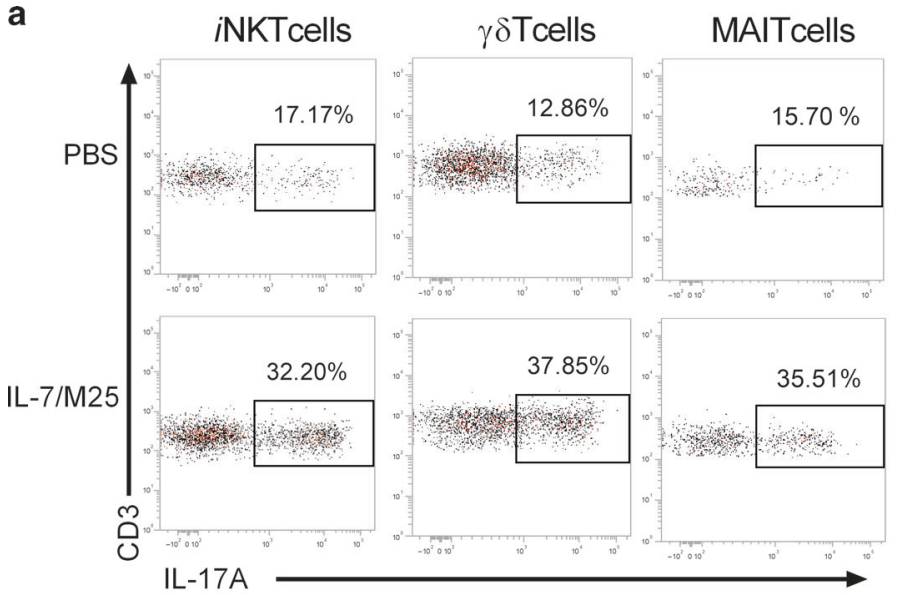

b
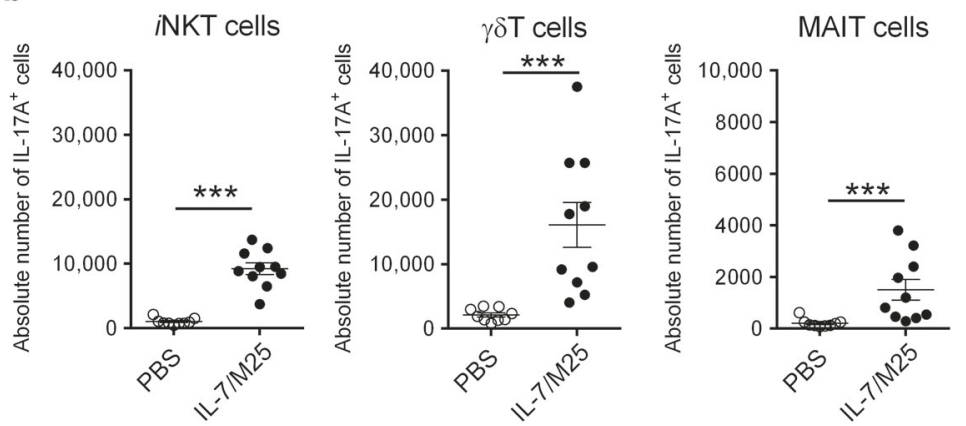

d
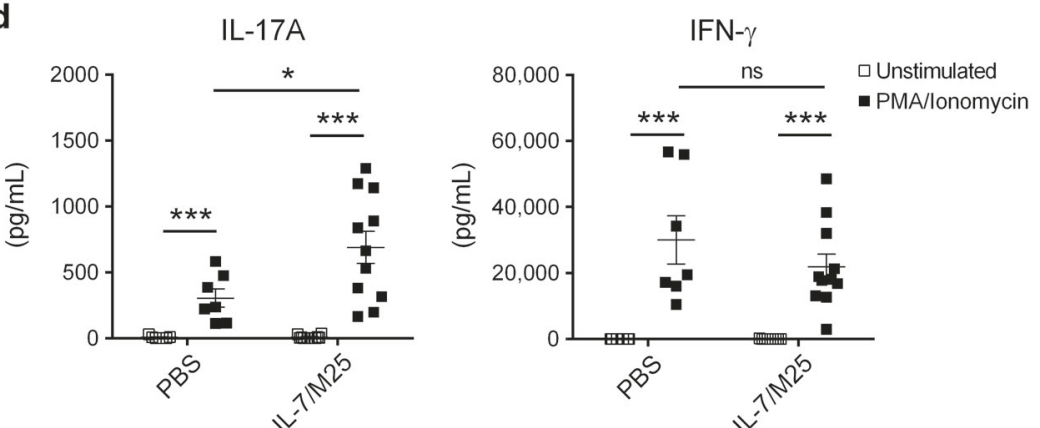

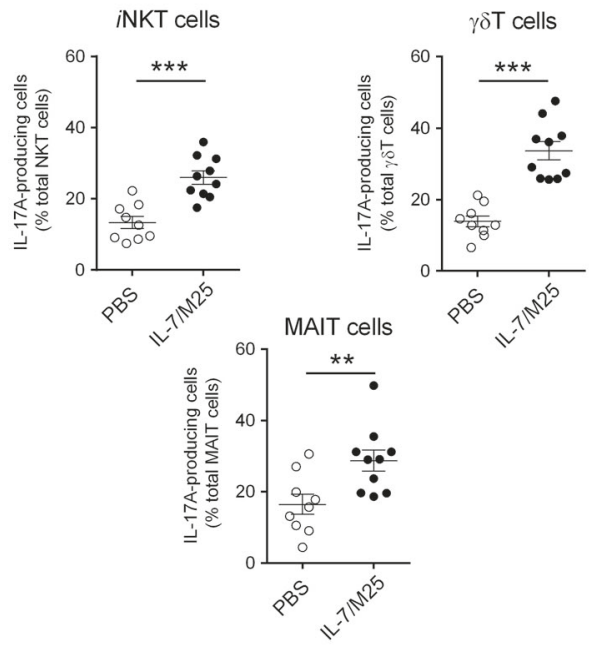

C

c $\quad$ PBS

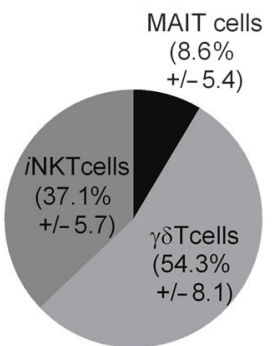

Proportion of each population in total IL-17A ${ }^{+}$innate Tcells

e

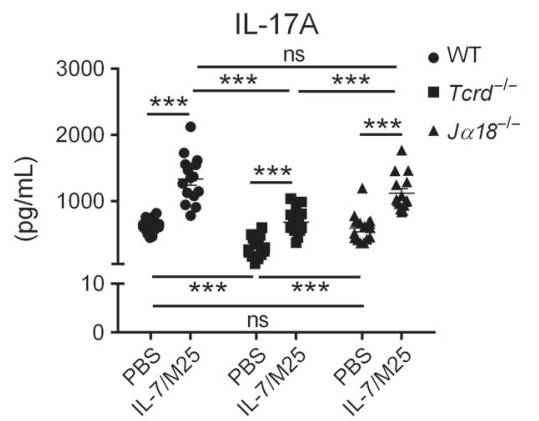

Fig. 2 IL-7/M25 increases IL-17A production by lung innate T cells. a-c Lung leukocytes from PBS- or IL-7/M25-treated mice were cultured for $4 \mathrm{~h}$ in complete RPMI 1640 medium in the presence of PMA/ionomycin. a Frequencies of IL-17A-producing innate T cells were evaluated by intracellular flow cytometry. Representative dot plots are shown in the left panel. Individual values and means \pm SEM from two independent experiments are shown (9-10 mice/group) in the right panel. b Absolute numbers of IL-17A-producing innate T cells. Individual values and means \pm SEM from two independent experiments are shown (9-10 mice/group). c Relative proportions of innate T-cell subsets within total IL17A-producing innate T cells in PBS- and IL-7/M25-treated mice. (d-e) Lung leukocytes from PBS- or IL-7/M25-treated mice were cultured in complete RPMI 1640 medium in the presence or not of PMA/ionomycin, and culture supernatants were collected after $20 \mathrm{~h}$. d Levels of IL-17A and IFN- $\gamma$ in culture supernatants. Individual values and means \pm SEM from two independent experiments are shown (7-11 mice/group). e Levels of IL-17A in culture supernatants of lung leukocytes from WT, $\mathrm{Tcrd}^{-1-}$, and Traj $18^{-/-}$mice. Individual values and means \pm SEM from three independent experiments are shown (7-15 mice/group). ns not significant, ${ }^{*} P<0.05 ;{ }^{* *} P<0.01 ;{ }^{* *} P<0.001$

$\gamma \delta T$ cells mainly populate the lung parenchyma, while the vasculature contains their IFN- $\gamma$-producing counterparts. ${ }^{29,42}$ Thus, $\mathrm{RORYt}^{+}$innate $\mathrm{T}$ cells appear to be poised on the front line to react to IL-7 instillation.

Conversely, the frequency of adaptive T-lymphocyte cells was not modulated upon IL-7 treatment, although a more detailed analysis is required to precisely gauge the effects of this cytokine on adaptive T-cell functions. However, this observation is of importance regarding possible oversecretion of cytokines and subsequent development of auto-inflammatory responses. The biology of innate lymphoid cells (ILCs) was shown to critically rely on IL-7. ${ }^{43,44}$ Thus, it is likely that lung RORyt ${ }^{+}$ILCs also expand upon IL-7 instillation. Accordingly, it will be worth to evaluate the contribution of these lymphocytes in the pro-IL-17A effect of IL-7, although their scarce representation in the lung tissue ${ }^{45}$ may restrict their role.

While IL-7 pretreatment elicited an innate T-cell-dependent control of S. pneumoniae outgrowth and dissemination, this approach failed to improve mouse survival. Previous studies have revealed the potent protective effect of innate T-cell 
a

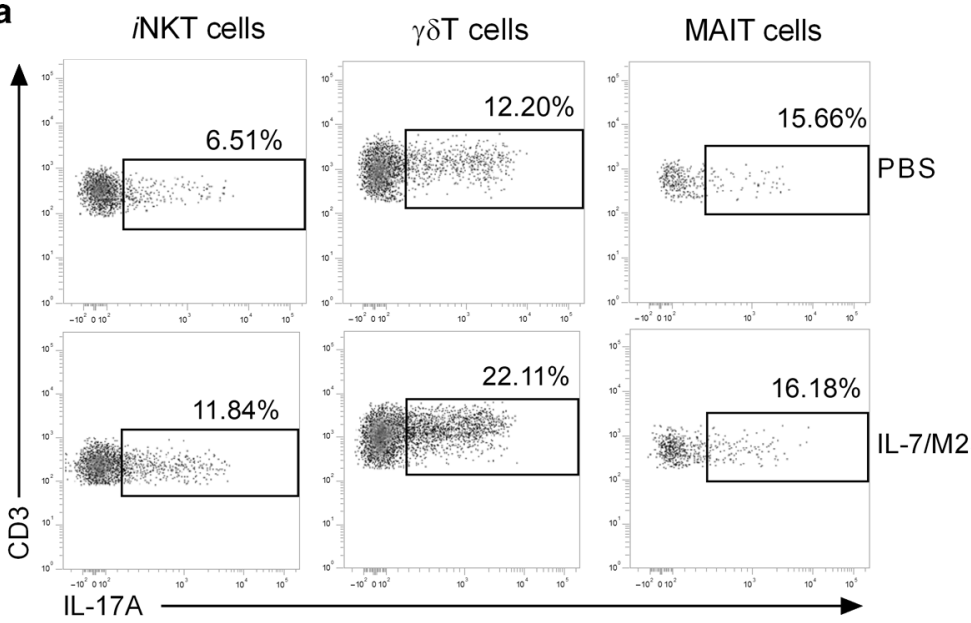

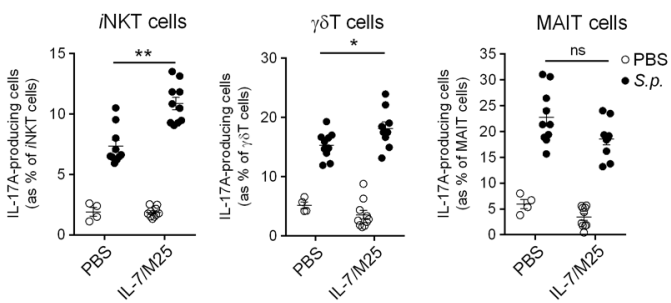

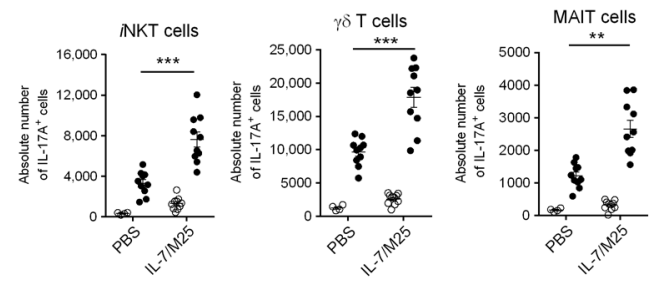

b
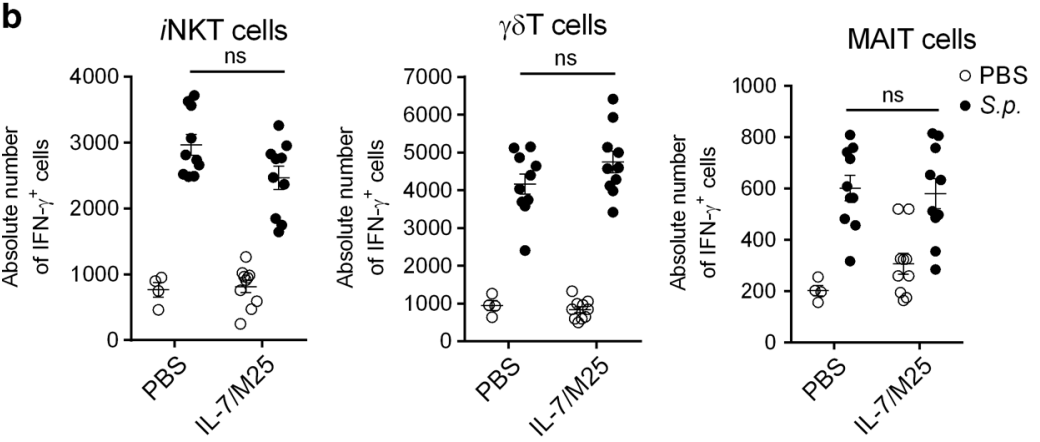
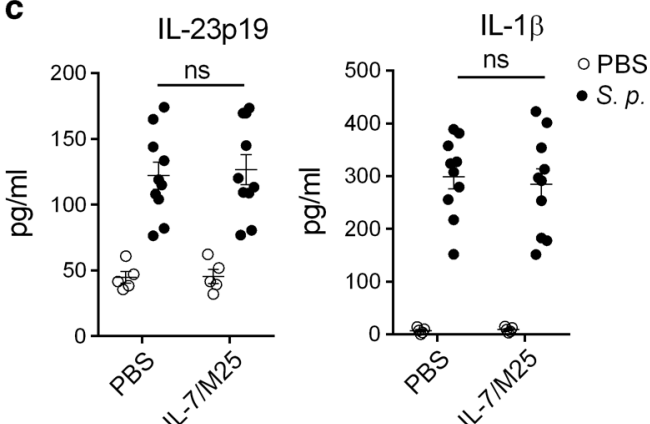

d

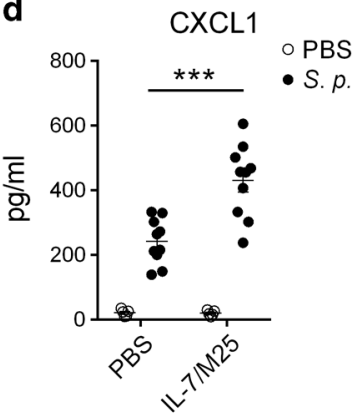

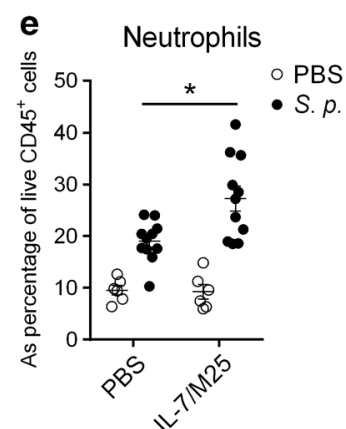

Fig. 3 IL-7/M25 treatment increases innate IL-17A response to pneumococcal infection. a-b PBS- or IL-7/M25-treated WT C57BL/6J mice were i.n. infected with S. pneumoniae $\left(2 \times 10^{6} \mathrm{cfu}\right)$ and euthanized $16 \mathrm{~h}$ post infection. a IL-17A production by lung innate T cells was evaluated by intracellular flow cytometry. Representative dot plots of IL-17A-producing innate T cells are shown in the left panel. Individual values and means \pm SEM of the frequencies and absolute numbers of IL-17A-producing innate $T$ cells from two independent experiments are shown (4-10 mice/group) in the right panel. b IFN- $\gamma$ production by lung innate T cells was evaluated by intracellular flow cytometry. Individual values and means \pm SEM of the number of IFN- $\gamma$-producing innate T cells from two independent experiments are shown (4-10 mice/group). c-f PBSor IL-7/M25-treated WT C57BL/6J mice were i.n. infected with S. pneumoniae $\left(2 \times 10^{6} \mathrm{cfu}\right)$ and euthanized $16 \mathrm{~h}$ post infection. Levels of IL$23 p 19, \mathrm{IL}-1 \beta$ (c), CXCL1 (d), and MPO (f) proteins were evaluated in homogenized lung tissue. Individual values and means \pm SEM from two

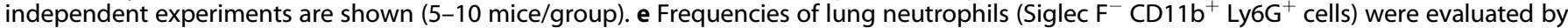
flow cytometry. Individual values and means \pm SEM from two independent experiments are shown (5-10 mice/group). ns not significant, ${ }^{*} P<$ $0.05 ;{ }^{* *} P<0.01 ;{ }^{* * *} P<0.001$

stimulators such as a-GalCer on experimental pneumococcusinduced lethal pneumonia. ${ }^{11,12}$ However, the use of high doses of a-GalCer is not without concern since it may lead to advert effects such as hyperinflammation, ${ }^{46}$ including airway hyperresponsiveness ${ }^{47}$ and/or long-term iNKT cell hyporesponsiveness. $^{39}$ Interestingly, our data indicated that the original combination of a low dose of a-GalCer with IL-7/M25 conferred an almost complete protection, while stand-alone treatments had marginal effects. From a translational point of view, limiting the appearance of iNKT cell hyporesponsiveness by using reduced dose of a-GalCer could be an interesting strategy to decrease the risk of secondary infections post-treatment. ${ }^{48}$ Consistent with our previous report, ${ }^{49} \mathrm{a}-\mathrm{GalCer}$ led to a $\gamma \delta \mathrm{T}$ cell transactivation culminating in a substantial increase production of IL-17A. Although the activation mechanisms need to be further investigated, it is also worth mentioning that our study reveals that MAIT cells get activated in a-GalCer-induced immune response. This should be considered in clinics in the context of a-GalCer-based therapies regarding the abundance of this population in humans. ${ }^{50}$ 

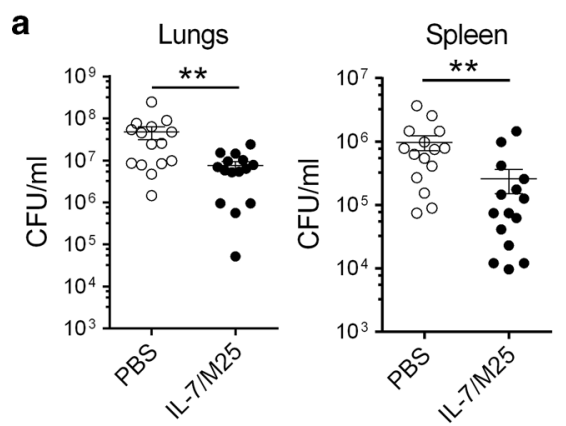

b

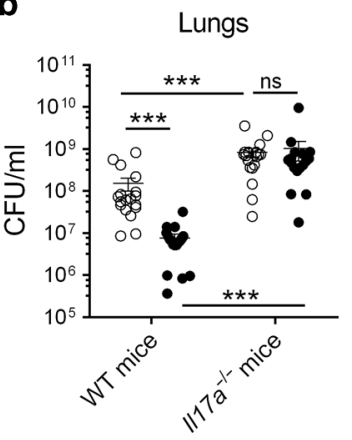

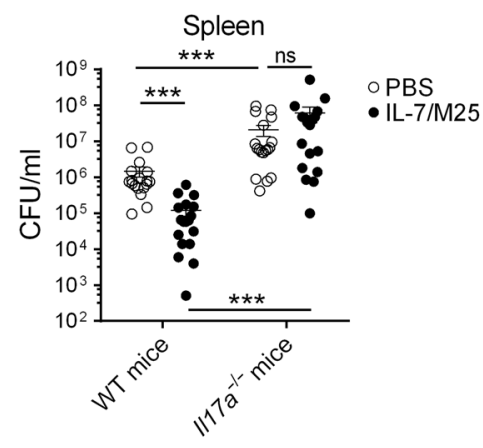

C

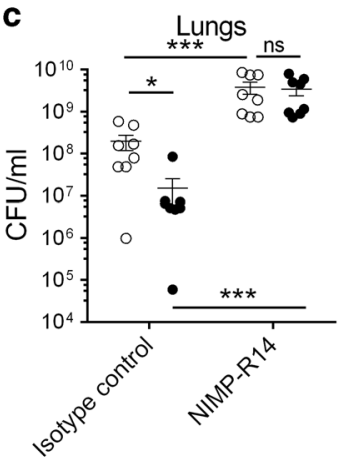

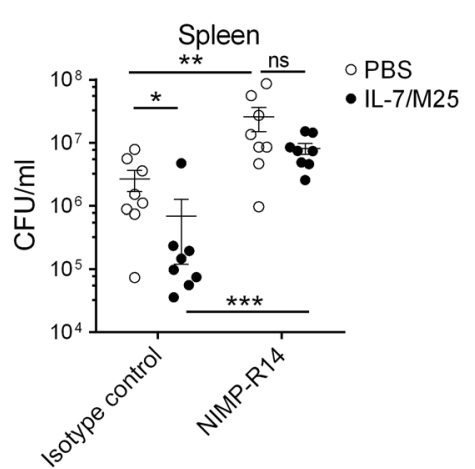

d
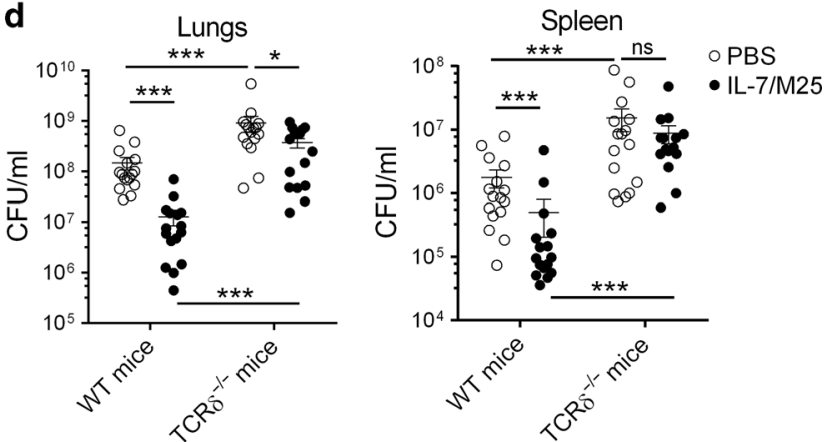

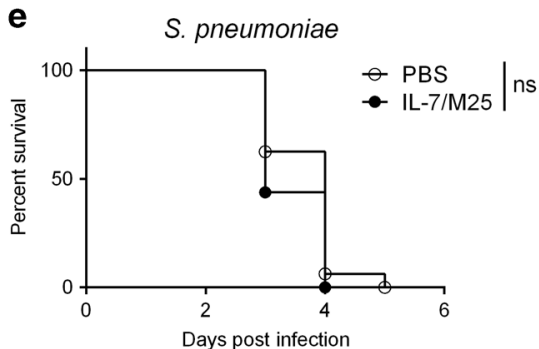

Fig. 4 Mechanisms involved in the antibacterial effect of IL-7/M25. a PBS- or IL-7/M25-treated WT C57BL/6J mice were i.n. infected with S. pneumoniae $\left(2 \times 10^{6} \mathrm{cfu}\right)$, and the number of CFU was determined $60 \mathrm{~h}$ post infection in the lungs (left panel) and in the spleen (right panel). Individual counts and means \pm SEM of two independent experiments are shown (15 mice/group). b PBS- or IL-7/M25-treated WT or $/ 17 a^{-/-}$ C57BL/6J mice were i.n. infected with S. pneumoniae $\left(2 \times 10^{6} \mathrm{cfu}\right)$, and the number of CFU was determined $60 \mathrm{~h}$ post infection in the lungs (left panel) and in the spleen (right panel). Individual counts and means \pm SEM of two independent experiments are shown (18 mice/group). c PBSor IL-7/M25-treated WT C57BL/6J mice treated i.p. with LTF2 or NIMP-R14 were i.n. infected with S. pneumoniae $\left(2 \times 10^{6} \mathrm{cfu}\right)$, and the number of CFU was determined $60 \mathrm{~h}$ post infection in the lungs (left panel) and in the spleen (right panel). Individual counts and means \pm SEM of one representative experiment out of two are shown (eight mice/group). d PBS- or IL-7/M25-treated WT or Tcrd ${ }^{-1-}$ C57BL/6 J mice were i.n. infected with S. pneumoniae ( $\left.2 \times 10^{6} \mathrm{cfu}\right)$, and the number of CFU was determined $60 \mathrm{~h}$ post infection in the lungs (left panel) and in the spleen (right panel). Individual counts and means \pm SEM of two independent experiments are shown (16 mice/group). e PBS- or IL-7/M25-treated WT C57BL/6J mice were i.n. infected with S. pneumoniae $\left(2 \times 10^{6} \mathrm{cfu}\right)$. Survival of mice was monitored daily (16 mice/group). ns, not significant; ${ }^{*} P<0.05 ; * * P<0.01 ; * * * P<0.001$

Clinically, manipulating IL-17 biology by means of IL-7 during lung infection has to be considered with caution, given the versatile nature of this cytokine. Thus, one can anticipate that IL7 may fuel inflammation. For instance, influenza virus infection triggers an intense and deleterious inflammatory host response ${ }^{51,52}$ that is partially mediated by IL-17A. ${ }^{53}$ Thus, neutralization of the IL-7/IL-17 axis may be more appropriate in this specific pathological situation. Nevertheless, severe influenza infections are followed by a phase of immunosuppression, during which subjects are more prone to develop secondary bacterial infections. ${ }^{54-57}$ The increased susceptibility to superinfections is partially due to the reduced IL-17A production by $\gamma \delta T$ cells in influenza virus-experienced hosts. ${ }^{30}$ Altogether, the decision to either foster or alleviate the IL-7/IL17 axis could be clearly different according to the type of infection, the time point of ongoing infection, and the anticipated outcome of the inflammatory immune response. In any case, this points toward a great potential for manipulating IL-7 biology during lung inflammation.

Some preclinical studies have previously shown a potential benefit for IL-7 during bacterial infections. For instance, repeated IL-7 injections during Mycobacterium tuberculosis infection improved mouse survival but did not influence granuloma formation and bacterial loads. ${ }^{58}$ In addition, a vaccination protocol by using a recombinant Mycobacterium bovis BCG expressing a $M$. tuberculosis Ag (Ag85B) was shown to increase Ag85B-specific $\mathrm{CD}^{+} \mathrm{T}$ cells in the lungs when combined with IL-7, an effect that relied on $\gamma \delta T 17$ cells. $^{59}$

Although few reports indicated its secretion upon acute infection, endogenous IL-7 was previously demonstrated critical during oral Citrobacter rodentium infection. ${ }^{60}$ In this model, blockade of the IL-7R signaling led to an impaired bacterial 


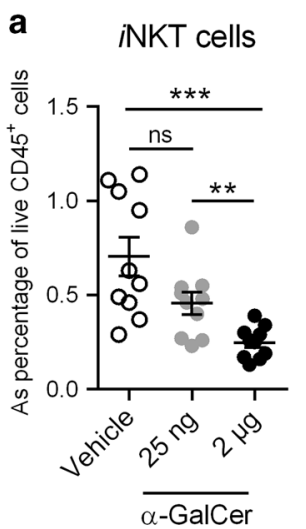

b

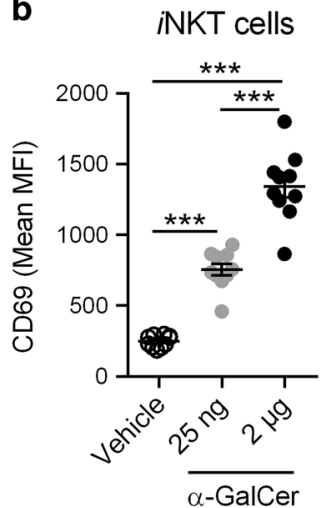

c

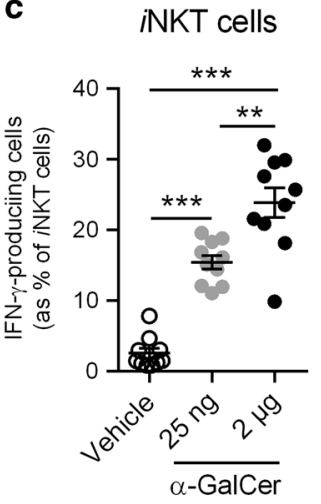

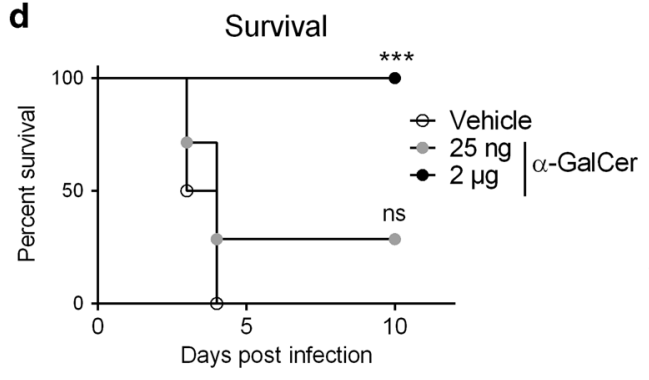

$\mathbf{e}$

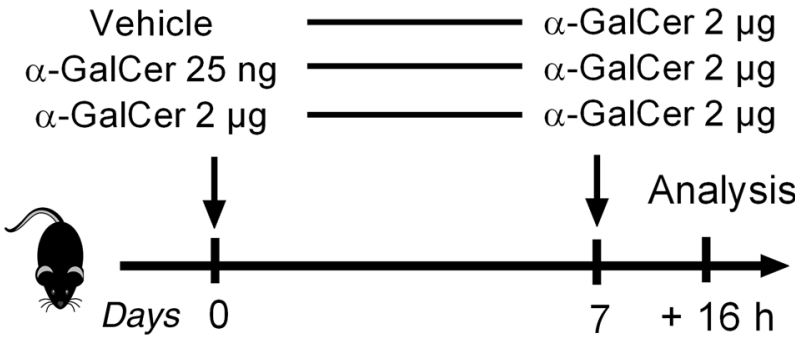

$\mathbf{f}$

iNKT cells

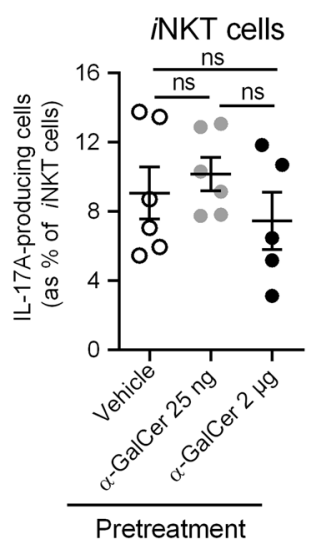

g

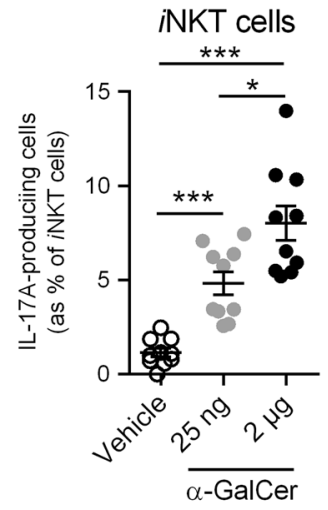

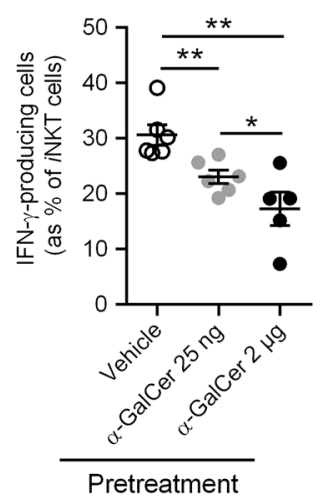

h

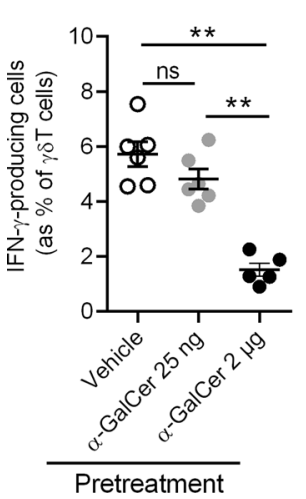

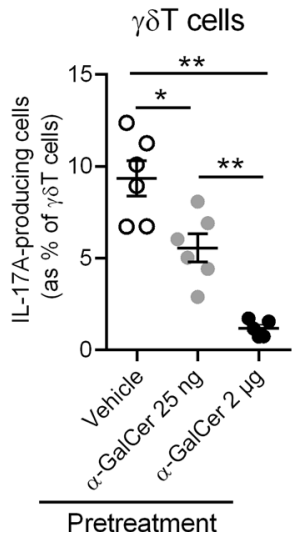

clearance and enhanced colon epithelium damages. ${ }^{60}$ Thus, the endogenous role of IL-7 in innate T-cell functions might be worth investigating in disease models in which its biological activity is modulated, such as in allergy or chronic viral infections. ${ }^{61-63}$

In conclusion, we reveal the ability of IL-7 i.n. instillation to preferentially fine-tune lung innate T-cell functions with a
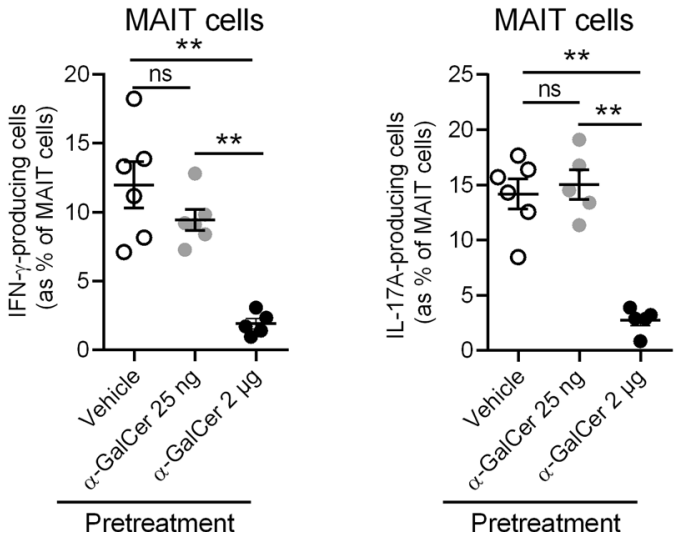

positive outcome on the host antibacterial response. This observation should be considered for the development of novel cytokine-based "immunointervention" strategies. By extension, neutralization of the IL-7/IL-17 axis may be pertinent in the context of IL-17-driven immunopathologies such as psoriasis, arthritis, and multiple sclerosis. 
Fig. 5 Dose-dependent effect of $\alpha$-GalCer instillation on lung innate immune response. a-d WT C57BL/6J mice were injected i.n. with vehicle or two doses of $\alpha$-GalCer $(25 \mathrm{ng}$ and $2 \mu \mathrm{g}$ ). Lungs were collected $16 \mathrm{~h}$ after injection, and $i \mathrm{NKT}$ cell activation was evaluated. a Frequencies of lung iNKT cells were evaluated between groups by flow cytometry. Individual values and means \pm SEM of iNKT cell frequencies from two independent experiments are shown (10 mice/group). b Expression of CD69 on lung iNKT cells. Individual values and means \pm SEM of mean fluorescence intensity from two independent experiments are shown (10 mice/group). c IFN- $\gamma$ and IL-17A production by lung iNKT cells was evaluated by intracellular flow cytometry. Individual values and means \pm SEM of the frequencies of IFN- $\gamma$ - and IL-17A-producing iNKT cells from two independent experiments are shown (10 mice/group). d Vehicle- or $\alpha$-GalCer-treated WT C57BL/6J mice were i.n. infected 16 h later with S. pneumoniae $\left(2 \times 10^{6} \mathrm{cfu}\right.$ ). Survival of mice was monitored daily (6-7 mice/group). e-g Vehicle- or $\alpha$-GalCer-pretreated WT C57BL/6J mice were challenged a week later with a high dose of $\alpha$-GalCer $(2 \mu \mathrm{g})$. Lung innate T-cell response was evaluated $16 \mathrm{~h}$ later. e Model to study $i$ NKT cell hyporesponsiveness. f IFN- $\gamma$ and IL-17A production by lung $i$ NKT cells was evaluated by intracellular flow cytometry. Individual values and means \pm SEM of the frequencies of IFN- $\gamma$ - and IL-17A-producing iNKT cells from two independent experiments are shown (5-6 mice/ group). $\mathbf{g}$ Expression of PD-1 on lung iNKT cells. Individual values and means \pm SEM of mean fluorescence intensity from two independent experiments are shown (5-6 mice/group). $\mathbf{h}$ IFN- $\gamma$ and IL-17A production by lung $\gamma \delta$ T and MAIT cells was evaluated by intracellular flow cytometry. Individual values and means \pm SEM of the frequencies of IFN- $\gamma$ - and IL-17A-producing $\gamma \delta T$ and MAIT cells from two independent experiments are shown (5-6 mice/group). ns not significant, ${ }^{*} P<0.05 ;{ }^{* *} P<0.01 ;{ }^{* * *} P<0.001$

\section{METHODS}

Mice

Inbred C57BL/6J mice were purchased from Janvier (Le Genest-St-

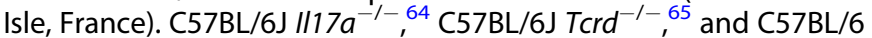
Traj18 ${ }^{-1-66}$ mice were bred and maintained in-house either at the Pasteur Institute of Lille and/or at the University of Tours under specific pathogen-free conditions, and were sex and age (8-10 weeks) matched. All animal work was conformed to the French governmental and committee guidelines for the care and use of animals for scientific purposes, and was approved by the national ethics committee under approval numbers 2015121722376405 and 201611151159949.

\section{Reagents and Abs}

Monoclonal antibodies against mouse CD45 (APC/Cy7- or AF700conjugated), CD3 (BV421- or PerCp-Cy5.5-conjugated), TCR (PerCp-Cy5.5-conjugated), NK1.1 (PeCy7- or BB700- or FITCconjugated), Ly6G (APC/Cy7- or AF700- or FITC-conjugated), CD11b (PerCP-Cy5.5- or FITC-conjugated), Siglec F (PE- or BV421conjugated), CD4 (PE- or efluor 450- or PerCP-Cy5.5-conjugated), CD8a (FITC- or APC-conjugated), CD127 (PeCy7-conjugated), CD19 (APC- or FITC-conjugated), Ki67 (FITC- or BV421-conjugated), RORyt (APC-conjugated), IL-17A (PE-conjugated), IFN- $\gamma$ (APCconjugated), and appropriate isotype controls were purchased from BioLegend (San Diego, CA, USA), BD Pharmingen (San Diego, CA, USA), and eBioscience (San Diego, CA, USA). PBS57 glycolipidloaded and control CD1d tetramers (APC- or PE-conjugated), as well as 5-OP-RU-loaded and control MR1 tetramers (BV421conjugated), were obtained from the National Institute of Allergy and Infectious Diseases Tetramer Facility (Emory University, Atlanta, GA). Mouse ELISA kits were purchased from R\&D systems (Lille, France), eBioscience, and Clinisciences (Nanterre, France). aGalCer (KRN7000) was purchased from Coger (Paris, France). Concanavalin (Con) A was purchased from Sigma-Aldrich (SaintQuentin-Fallavier, France).

\section{IL-7/M25 mAb complexes}

rhlL-7 (Miltenyi Biotec, Paris, France) was mixed with anti-IL-7 mAb (M25, BioXCell, West Lebanon, $\mathrm{NH}$ ) and incubated at $37^{\circ} \mathrm{C}$ for 30 min as previously described. ${ }^{21}$ Mice were injected i.n. with $400 \mathrm{ng}$ of cytokine $+2 \mu \mathrm{g}$ of $\mathrm{mAb}$ in $40 \mu \mathrm{l}$ of saline.

In vitro assays

Lungs were harvested from saline- or IL-7/M25-treated mice, and cell suspensions were prepared as previously described. Leukocytes were cultured for $20 \mathrm{~h}$ in complete RPMI 1640 medium containing or not phorbol 12-myristate 13-acetate (PMA) (100 ng/ $\mathrm{ml})$ and ionomycin $(1 \mu \mathrm{g} / \mathrm{ml})$.

Infection with S. pneumoniae and bacterial counts S. pneumoniae serotype 1 clinical isolate E1586 sequence type ST304 has been described elsewhere. ${ }^{29}$ Mice were anesthetized and administered i.n. with $50 \mu$ l of PBS containing live bacteria $\left(2 \times 10^{6} \mathrm{CFU}\right)$. Viable bacteria in the lungs and spleen were counted $36 \mathrm{~h}$ after $S$. pneumoniae infection by plating serial tenfold dilutions of lung or spleen homogenates onto blood $(5 \%)$ agar-agar-containing Petri dishes. The plates were incubated at $37^{\circ} \mathrm{C}$ with $5 \%$ of $\mathrm{CO}_{2}$, and CFUs were counted $24 \mathrm{~h}$ later.

Preparation of pulmonary immune cells

Mice were treated or not every other day with three doses of IL-7/ M25 complex and/or a-GalCer i.n., and then infected or not with S. pneumoniae. Lung mononuclear cells (MNCs) were prepared as previously described. ${ }^{29}$ Briefly, lungs were perfused with saline, harvested, and finely minced by using scissors. Lung pieces were then digested in a medium containing $1 \mathrm{mg} / \mathrm{ml}$ of collagenase type VIII (Sigma-Aldrich) and $1 \mu \mathrm{g} / \mathrm{ml}$ of DNase type I (Roche; Meylan, France) for $20 \mathrm{~min}$ at $37^{\circ} \mathrm{C}$ under gentle agitation. After washes, lung homogenates were resuspended in a $20 \%$ Percoll gradient, and centrifuged without brake at $2000 \mathrm{rpm}$ for $15 \mathrm{~min}$ at room temperature. Pellets were recovered in PBS $2 \%$ FCS, and erythrocytes were removed by using a red- blood cell lysis buffer (Sigma-Aldrich).

\section{Measurement of cytokines in the lungs}

Perfused lungs were collected in liquid nitrogen until processing. An anti-protease solution was prepared by dissolving one tablet of anti-protease $(25 \times)$ in $2 \mathrm{ml}$ of distilled water. T-Per Tissue protein extraction buffer $(1 \mathrm{ml})$ containing $1 \mathrm{x}$ of the anti-protease solution was added onto lungs and homogenized for $1 \mathrm{~min}$. Lung lysates were kept on ice for $20 \mathrm{~min}$ and then centrifuged at 10,000 rpm for $15 \mathrm{~min}$. The supernatants were collected and stored at $-20^{\circ} \mathrm{C}$ until analysis.

\section{Assessment of lung 117 expression by quantitative reverse} transcription-PCR

Total RNA from whole lungs of PBS-treated or S. pneumoniaeinfected mice was extracted and purified by using the NucleoSpin RNA Extraction Kit (Macherey-Nagel; Hoerdt, France) following the manufacturer's instructions. The cDNA was synthesized from total RNA by using the High Capacity RNA-to-cDNA Kit (Thermofisher Scientific; Les Ulis, France). Gene expression was determined on the QuantStudio $12 \mathrm{~K}$ Flex Real-Time PCR System (Thermofisher Scientific) by using specific primers, as previously described, ${ }^{67}$ and QuantiTect SYBR Green PCR Master Mix (Qiagen; Courtaboeuf, France) according to the manufacturer's instructions. Gene expression was normalized to Gapdh.

\section{Flow cytometry}

Cells were incubated in RPMI 1640 5\% FCS containing Golgi Plug/ Golgi Stop (BD Biosciences) for $2 \mathrm{~h}$ at $37^{\circ} \mathrm{C}$. Then, cells were stained with appropriate dilutions of antibodies $\left(30 \mathrm{~min}, 4^{\circ} \mathrm{C}\right.$ ) in PBS 2\% FCS. Cells were washed and fixed by using Intracellular Fixation Buffer (eBioscience, CliniSciences, Montrouge, France). 
a
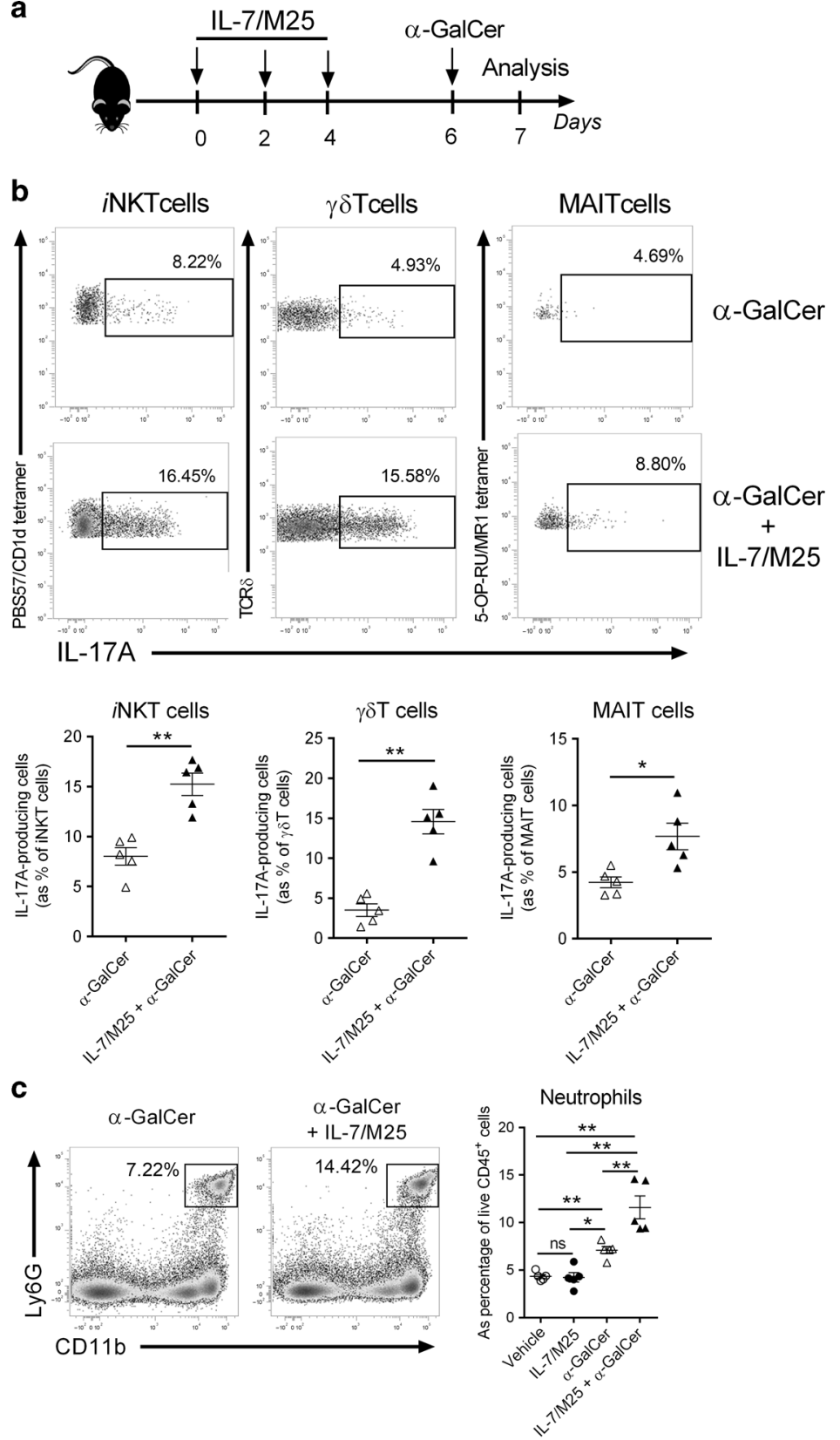

d

Survival

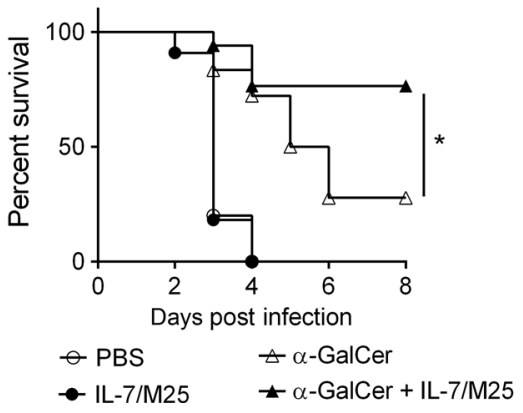

Fixed cells were then permeabilized in Permeabilization Buffer (eBioscience) according to the manufacturer's instructions. Intranuclear staining was performed by using the True-Nuclear transcription factor buffer set (BioLegend) according to the manufacturer's instructions. Dead cells were stained with the LIVE/DEAD Fixable Aqua Dead Cell Staining kit (Thermofisher Scientific). Cells were stained with PE-conjugated $\mathrm{mAb}$ against IL$17 \mathrm{~A}$ or APC-conjugated $\mathrm{mAb}$ against IFN- $\gamma$, and acquired on either 
Fig. 6 IL-7/M25 plus $\alpha$-GalCer enhances IL-17A innate T-cell response and survival of S. pneumoniae-infected mice. a WT C57BL/6J mice received three intranasal doses of IL-7/M25 or saline every other day. Then, mice received $\alpha$-GalCer ( $25 \mathrm{ng}$ ) at day 6 by i.n. route. b IL-17A production by lung innate T cells was evaluated by intracellular flow cytometry $16 \mathrm{~h}$ after $\alpha$-GalCer instillation. Representative dot plots of IL17A-producing innate T cells are shown in the upper panel. Individual values and means \pm SEM from one representative experiment out of two are shown (five mice/group) in the lower panel. c Frequencies of lung neutrophils (Siglec $\mathrm{F}^{-} \mathrm{CD}_{11 \mathrm{~b}^{+}} \mathrm{Ly}_{6 \mathrm{G}}{ }^{+}$cells) were evaluated $16 \mathrm{~h}$ after $\alpha$-GalCer instillation. Representative dot plots are shown in the left panel. Individual values and means \pm SEM from one representative experiment out of two are shown (five mice/group). d Mice were i.n. infected with S. pneumoniae $\left(2 \times 10^{6} \mathrm{cfu}\right) 16 \mathrm{~h}$ after $\alpha$-GalCer instillation, and survival was monitored daily (11-18 mice/group). ns not significant, ${ }^{*} P<0.05 ;{ }^{* *} P<0.01$

a LSR Fortessa cytometer (BD Biosciences) or a MACS Quant (Miltenyi Biotec). Analyses were performed by using the VenturiOne software (Applied Cytometry; Sheffield, UK).

Neutrophil depletion

Neutrophil-depleting anti-Ly6G monoclonal antibodies were purified in-house (by using protein $\mathrm{G}$ columns) from supernatants of the NIMP-R14 hybridoma. Neutrophils were depleted $24 \mathrm{~h}$ before S. pneumoniae infection by using NIMP-R14 $(100 \mu \mathrm{g}$ per mouse i.p. in $200 \mu \mathrm{l}$ of PBS). A rat lgG2b isotype control antibody (clone LTF2; BioXcell) was used as a control.

\section{Statistical analysis}

All statistical analysis was performed by using GraphPad Prism software. The statistical significance was evaluated by using nonparametric Mann-Whitney $U$ tests or Kruskal-Wallis to compare the means of biological replicates in each experimental group. Survival rates after $S$. pneumoniae challenge were analyzed by using a log-rank test. The results with a $P$ value of $<0.05$ were considered significant. ns: not significant; ${ }^{*} p<0.05 ;{ }^{* *} p<0.01$; ${ }^{* * *} p<0.001$.

\section{ACKNOWLEDGEMENTS}

This work was funded with support by the Région Centre-Val de Loire under the program "ARD 2020 Biomédicaments" (Project 7UP and Primine) and by the French Higher Education and Research ministry under the program "Investissements d'avenir": LabEx MAblmprove (ANR-10-LABX-53-01). Y.J., N.H-V., J.C.S., C.F., M.Si-T., and C.P. are supported by Inserm. F.T. is supported by CNRS. T.B., L.G., and C.B. are supported by the University of Tours. D.S. is supported by the Pasteur Institute of Lille. M.H. was the recipient of a doctoral fellowship from the AZM foundation. Y.J. was the recipient of the "Antoine RABBAT" doctoral fellowship from the "Fonds de Recherche en Santé Respiratoire" under the support of the "Fondation du Souffle". E. C.P. was supported by a postdoctoral fellowship from the French Institute of cancer (INCa). We also thank the Pasteur Institute of Lille and University of Tours animal facilities for excellent mouse husbanding. We thank the NIH tetramer core facility (Emory University) for providing CD1d and MR1 tetramers. The MR1:5-OP-RU tetramer technology was developed jointly by J. McCluskey, J. Rossjohn, and D. Fairlie, and the material was produced by the NIH Tetramer Core Facility as permitted to be distributed by the University of Melbourne.

\section{AUTHOR CONTRIBUTIONS}

M.H., Y.J., T.B., and C.P. designed the study, analyzed the data, and wrote the paper with input from the other authors. F.T. and M.Si-T. discussed the data and edited the paper. M.H., Y.J., F.C., D.S., C.B., L.G., E.C.P., T.B., and C.P. performed the experiments with assistance from N.H-V., J-C.S., and C.F. Important mice, reagents, experimental, and data analysis techniques were provided by J-C.S. and F.T.

\section{ADDITIONAL INFORMATION}

The online version of this article (https://doi.org/10.1038/s41385-019-0212-y) contains supplementary material, which is available to authorized users.

Competing interests: The authors declare no competing interests.

Publisher's note Springer Nature remains neutral with regard to jurisdictional claims in published maps and institutional affiliations.

\section{REFERENCES}

1. Godfrey, D. I., Uldrich, A. P., McCluskey, J., Rossjohn, J. \& Moody, D. B. The burgeoning family of unconventional T cells. Nat. Immunol. 16, 1114-1123 (2015).

2. Bendelac, A., Savage, P. B. \& Teyton, L. The biology of NKT cells. Annu. Rev. Immunol. 25, 297-336 (2007).

3. Bonneville, M., O'Brien, R. L. \& Born, W. K. Gammadelta T cell effector functions: a blend of innate programming and acquired plasticity. Nat. Rev. Immunol. 10, 467-478 (2010).

4. Le Bourhis, L. et al. Antimicrobial activity of mucosal-associated invariant T cells. Nat. Immunol. 11, 701-708 (2010).

5. Rouxel, O. et al. Cytotoxic and regulatory roles of mucosal-associated invariant T cells in type 1 diabetes. Nat. Immunol. 18, 1321-1331 (2017).

6. Godfrey, D. I., Le Nours, J., Andrews, D. M., Uldrich, A. P. \& Rossjohn, J. Unconventional T cell targets for cancer immunotherapy. Immunity 48, 453-473 (2018).

7. Cerundolo, V. \& Salio, M. Harnessing NKT cells for therapeutic applications. Curr. Top. Microbiol. Immunol. 314, 325-340 (2007).

8. Cerundolo, V., Silk, J. D., Masri, S. H. \& Salio, M. Harnessing invariant NKT cells in vaccination strategies. Nat. Rev. Immunol. 9, 28-38 (2009).

9. Chiplunkar, S., Dhar, S., Wesch, D. \& Kabelitz, D. Gammadelta T cells in cancer immunotherapy: current status and future prospects. Immunotherapy 1, 663-678 (2009).

10. Bedard, M., Salio, M. \& Cerundolo, V. Harnessing the power of invariant natural killer T cells in cancer immunotherapy. Front. Immunol. 8, 1829 (2017).

11. Kawakami, K. et al. Critical role of Valpha14+ natural killer T cells in the innate phase of host protection against Streptococcus pneumoniae infection. Eur. J. Immunol. 33, 3322-3330 (2003).

12. Ivanov, S. et al. Key role for respiratory CD103(+) dendritic cells, IFN- $\gamma$, and IL-17 in protection against Streptococcus pneumoniae infection in response to agalactosylceramide. J. Infect. Dis. 206, 723-734 (2012).

13. Wiles, M. V., Ruiz, P. \& Imhof, B. A. Interleukin-7 expression during mouse thymus development. Eur. J. Immunol. 22, 1037-1042 (1992).

14. Fry, T. J. \& Mackall, C. L. The many faces of IL-7: from lymphopoiesis to peripheral T cell maintenance. J. Immunol. 174, 6571-6576 (2005).

15. Palmer, M. J. et al. Interleukin-7 receptor signaling network: an integrated systems perspective. Cell. Mol. Immunol. 5, 79-89 (2008).

16. Mackall, C. L., Fry, T. J. \& Gress, R. E. Harnessing the biology of IL-7 for therapeutic application. Nat. Rev. Immunol. 11, 330-342 (2011).

17. Gao, J., Zhao, L., Wan, Y. Y. \& Zhu, B. Mechanism of action of IL-7 and its potential applications and limitations in cancer immunotherapy. Int. J. Mol. Sci. 16, 10267-10280 (2015)

18. Finkelman, F. D. et al. Anti-cytokine antibodies as carrier proteins. Prolongation of in vivo effects of exogenous cytokines by injection of cytokine-anti-cytokine antibody complexes. J. Immunol. 151, 1235-1244 (1993).

19. Boyman, O., Ramsey, C., Kim, D. M., Sprent, J. \& Surh, C. D. IL-7/anti-IL-7 mAb complexes restore $T$ cell development and induce homeostatic T Cell expansion without lymphopenia. J. Immunol. 180, 7265-7275 (2008).

20. Michel, M.-L. et al. Interleukin 7 (IL-7) selectively promotes mouse and human IL17-producing $\gamma \delta$ cells. Proc. Natl Acad. Sci. USA 109, 17549-17554 (2012).

21. Webster, K. E. et al. IL-17-producing NKT cells depend exclusively on IL-7 for homeostasis and survival. Mucosal Immunol. 7, 1058-1067 (2014).

22. Hameg, A. et al. IL-7 up-regulates IL-4 production by splenic NK1.1+ and NK1.1MHC class I-like/CD1-dependent CD4+ T cells. J. Immunol. 162, 7067-7074 (1999).

23. Tang, X.-Z. et al. IL-7 licenses activation of human liver intrasinusoidal mucosalassociated invariant T cells. J. Immunol. 190, 3142-3152 (2013).

24. Gracey, E. et al. IL-7 primes IL-17 in mucosal-associated invariant T (MAIT) cells, which contribute to the Th17-axis in ankylosing spondylitis. Ann. Rheum. Dis. 75, 2124-2132 (2016).

25. Guggino, G. et al. IL-17 polarization of MAIT cells is derived from the activation of two different pathways. Eur. J. Immunol. 47, 2002-2003 (2017).

26. Willing, A., Jäger, J., Reinhardt, S., Kursawe, N. \& Friese, M. A. Production of IL-17 by MAIT cells is increased in multiple sclerosis and is associated with IL-7 receptor expression. J. Immunol. 200, 974-982 (2018). 
27. Nembrini, C., Marsland, B. J. \& Kopf, M. IL-17-producing T cells in lung immunity and inflammation. J. Allergy Clin. Immunol. 123, 986-994 (2009).

28. Sutton, C. E., Mielke, L. A. \& Mills, K. H. G. IL-17-producing $\gamma \delta ~ T$ cells and innate lymphoid cells. Eur. J. Immunol. 42, 2221-2231 (2012).

29. Hassane, M. et al. Neutrophilic NLRP3 inflammasome-dependent IL-1 $\beta$ secretion regulates the $\gamma \delta T 17$ cell response in respiratory bacterial infections. Mucosal. Immunol. 10, 1056-1068 (2017).

30. Cao, J. et al. Activation of IL-27 signalling promotes development of postinfluenza pneumococcal pneumonia. EMBO Mol. Med. 6, 120-140 (2014).

31. Paget, $C$. et al. CD3bright signals on $\gamma \delta$ T cells identify IL-17A-producing $V \gamma 6 \mathrm{~V} \delta 1+$ T cells. Immunol. Cell Biol. 93, 198-212 (2015).

32. Kurioka, A. et al. Diverse Streptococcus pneumoniae strains drive a mucosalassociated invariant T-cell response through major histocompatibility complex class I-related molecule-dependent and cytokine-driven pathways. J. Infect. Dis. 217, 988-999 (2018)

33. Hartmann, N. et al. Riboflavin metabolism variation among clinical isolates of Streptococcus pneumoniae results in differential activation of MAIT cells. Am. J. Respir. Cell Mol. Biol. https://doi.org/10.1165/rcmb.2017-02900C (2018).

34. Hausdorff, W. P., Feikin, D. R. \& Klugman, K. P. Epidemiological differences among pneumococcal serotypes. Lancet Infect. Dis. 5, 83-93 (2005)

35. Sutton, C. E. et al. Interleukin-1 and IL-23 induce innate IL-17 production from gammadelta T cells, amplifying Th17 responses and autoimmunity. Immunity $\mathbf{3 1}$ 331-341 (2009).

36. Doisne, J.-M. et al. Cutting edge: crucial role of IL-1 and IL-23 in the innate IL-17 response of peripheral lymph node NK1.1- invariant NKT cells to bacteria. J. Immunol. 186, 662-666 (2011).

37. Kolls, J. K. \& Lindén, A. Interleukin-17 family members and inflammation. Immunity 21, 467-476 (2004).

38. Fujii, S., Shimizu, K., Kronenberg, M. \& Steinman, R. M. Prolonged IFN-gammaproducing NKT response induced with alpha-galactosylceramide-loaded DCs. Nat. Immunol. 3, 867-874 (2002).

39. Parekh, V. V. et al. Glycolipid antigen induces long-term natural killer T cell anergy in mice. J. Clin. Invest. 115, 2572-2583 (2005).

40. Burdin, N., Brossay, L. \& Kronenberg, M. Immunization with alphagalactosylceramide polarizes CD1-reactive NK T cells towards Th2 cytokine synthesis. Eur. J. Immunol. 29, 2014-2025 (1999).

41. Parekh, V. V. et al. PD-1/PD-L blockade prevents anergy induction and enhances the anti-tumor activities of glycolipid-activated invariant NKT cells. J. Immunol. 182, 2816-2826 (2009).

42. Lee, Y. J. et al. Tissue-specific distribution of iNKT cells impacts their cytokine response. Immunity 43, 566-578 (2015).

43. Vonarbourg, C. \& Diefenbach, A. Multifaceted roles of interleukin-7 signaling for the development and function of innate lymphoid cells. Semin. Immunol. 24, 165-174 (2012).

44. Satoh-Takayama, N. et al. IL-7 and IL-15 independently program the differentiation of intestinal CD3-NKp46+ cell subsets from Id2-dependent precursors. J. Exp. Med. 207, 273-280 (2010).

45. Kim, C. H., Hashimoto-Hill, S. \& Kim, M. Migration and tissue tropism of innate lymphoid cells. Trends Immunol. 37, 68-79 (2016).

46. Biburger, M. \& Tiegs, G. Alpha-galactosylceramide-induced liver injury in mice is mediated by TNF-alpha but independent of Kupffer cells. J. Immunol. 175, 1540-1550 (2005).
47. Meyer, E. H. et al. Glycolipid activation of invariant T cell receptor + NK T cells is sufficient to induce airway hyperreactivity independent of conventional CD4+ T cells. Proc. Natl Acad. Sci. USA 103, 2782-2787 (2006).

48. Barthelemy, A. et al. Influenza A virus-induced release of interleukin-10 inhibits the anti-microbial activities of invariant natural killer $\mathrm{T}$ cells during invasive pneumococcal superinfection. Mucosal Immunol. 10, 460-469 (2017).

49. Paget, C., Chow, M. T., Duret, H., Mattarollo, S. R. \& Smyth, M. J. Role of $\gamma \delta$ T cells in a-galactosylceramide-mediated immunity. J. Immunol. 188, 3928-3939 (2012).

50. Treiner, E. et al. Selection of evolutionarily conserved mucosal-associated invariant T cells by MR1. Nature 422, 164-169 (2003).

51. Snelgrove, R. J., Godlee, A. \& Hussell, T. Airway immune homeostasis and implications for influenza-induced inflammation. Trends Immunol. 32, 328-334 (2011).

52. Le Goffic, R. et al. Detrimental contribution of the Toll-like receptor (TLR) 3 to influenza A virus-induced acute pneumonia. PLoS Pathog. 2, e53 (2006).

53. Crowe, C. R. et al. Critical role of IL-17RA in immunopathology of influenza infection. J. Immunol. 183, 5301-5310 (2009).

54. McCullers, J. A. The co-pathogenesis of influenza viruses with bacteria in the lung Nat. Rev. Microbiol. 12, 252-262 (2014).

55. Metzger, D. W. \& Sun, K. Immune dysfunction and bacterial coinfections following influenza. J. Immunol. 191, 2047-2052 (2013).

56. Sun, J., Madan, R., Karp, C. L. \& Braciale, T. J. Effector T cells control lung inflammation during acute influenza virus infection by producing IL-10. Nat. Med. 15, 277-284 (2009)

57. Robinson, K. M., Kolls, J. K. \& Alcorn, J. F. The immunology of influenza virusassociated bacterial pneumonia. Curr. Opin. Immunol. 34, 59-67 (2015).

58. Maeurer, M. J. et al. Interleukin-7 or interleukin-15 enhances survival of Mycobacterium tuberculosis-infected mice. Infect. Immun. 68, 2962-2970 (2000).

59. Hatano, $S$. et al. Recombinant mycobacterium bovis bacillus calmette-guérin expressing Ag85B-IL-7 fusion protein enhances IL-17A-producing innate $\gamma \delta$ T cells. Vaccine 34, 2490-2495 (2016).

60. Zhang, W., Du, J.-Y., Yu, Q. \& Jin, J.-O. Interleukin-7 produced by intestinal epithelial cells in response to Citrobacter rodentium infection plays a major role in innate immunity against this pathogen. Infect. Immun. 83, 3213-3223 (2015).

61. Beq, S., Delfraissy, J.-F. \& Theze, J. Interleukin-7 (IL-7): immune function, involvement in the pathogenesis of HIV infection and therapeutic potential. Eur. Cytokine Netw. 15, 279-289 (2004).

62. Reeder, K. M. et al. The common $\gamma$-chain cytokine IL-7 promotes immunopathogenesis during fungal asthma. Mucosal Immunol. 11, 1352-1362 (2018).

63. Kelly, E. A. B. et al. Potential contribution of IL-7 to allergen-induced eosinophilic airway inflammation in asthma. J. Immunol. 182, 1404-1410 (2009).

64. Nakae, S. et al. Antigen-specific T cell sensitization is impaired in IL-17-deficient mice, causing suppression of allergic cellular and humoral responses. Immunity 17, 375-387 (2002)

65. Itohara, S. et al. T cell receptor delta gene mutant mice: independent generation of alpha beta T cells and programmed rearrangements of gamma delta TCR genes. Cell 72, 337-348 (1993).

66. Chandra, S. et al. A new mouse strain for the analysis of invariant NKT cell function. Nat. Immunol. 16, 799-800 (2015).

67. Patin, E. C. et al. Type I IFN receptor signaling controls IL7-dependent accumulation and activity of protumoral IL17A-producing $\gamma \delta T$ cells in breast cancer. Cancer Res. 78, 195-204 (2018). 